\title{
ENERGY WILLOW FROM EXPERIMENTAL PLANTATION AS A POTENTIALLY CLEAN ENERGY SOURCE
}

\author{
WIERZBA ENERGETYCZNA Z PLANTACJI EKSPERYMENTALNEJ \\ JAKO POTENCJALNIE CZYSTE ŹRÓDŁO ENERGII
}

\begin{abstract}
Energy willow as a species with broad adaptation possibilities, large production capacity and a wide range of applications, takes a special place among the plants grown for energy production. In this work an analysis was conducted in respect of the usefulness of this type of wood from experimental plantations as a clean source of energy generated in the combustion process. The heat of combustion and net calorific value of dry matter of energy willow wood, including selected sorts and classes of thickness were determined. Energy willow has a natural ability to accumulate heavy metals which are oxidized during the combustion process or remain in the ash, and consequently repollute the environment. In order to determine the environmental impact the content of heavy metals was examined in energy willow wood and in the soil of the experimental plantation. Metal concentrations were determined by the Atomic Absorption Spectrometry method (AAS). Results of the tests confirmed a close relationship between the heat of combustion, calorific value and wood thickness as well as its location in the tree structure. Furthermore, very large differences were found in the content of heavy metals in the samples of both willow wood and soil. The levels of heavy metal content in the wood of energy willow determine the agricultural use of ashes produced during combustion.
\end{abstract}

Keywords: energy willow, heavy metals, calorific value, heat of combustion

\section{Introduction}

Currently, we witness a progressive urbanization on a growing range of areas. As a result, industry is developing and communication routes are extended. This development is accompanied by increasing emissions of heavy metals which persist in the atmosphere and are deposited in the soil, thus contributing to the increase of agricultural wasteland. Production of plants for consumption in these areas becomes impossible due to the degree of contamination or because of unprofitability. These areas include, among others, infertile soil of lower quality class, polluted arable land in the vicinity of industrial plants, brownfield land (mining dumps) or reclaimed areas [1-3].

In view of the growing problems possibly quick and inexpensive solutions have been searched for. Currently, studies are being conducted on the usefulness of plants for the reclamation and management of contaminated soils. It has been observed that some plant

\footnotetext{
${ }^{1}$ Faculty of Process and Environmental Engineering, Lodz University of Technology, ul. Wólczańska 175, 90-924 Łódź, Poland, phone +48 426313779

*Corresponding author: monika.janas@dokt.p.lodz.pl
} 
species have a natural ability of accumulating heavy metals, i.e. of phytoremediation, so that they can be used in the process of purification of the environment. This group of plants with phytoremediation potential includes most plants grown for energy purposes. Special place is occupied here by energy willow as a species with wide adaptation possibilities and high production potential [4-6].

The ability of accumulation and disposal of harmful substances allows to use willow in the process of phytoremediation combining the function of bioenergy production with the function of improving the properties of the contaminated soil. An important factor limiting the use of willow for energy purposes is the accumulation in willow wood heavy metals taken from the environment. During the combustion process, these metals can be re-emitted into the environment or remain in the ashes, thus impeding their use and at the same time contribute to the re-contamination of surrounding [5,6].

Energy willow is not very demanding in terms of soil conditions [7, 8]. It can be grown both in the depression areas of Zulawy and on the foothills of the height from 350 to $550 \mathrm{~m}$ above sea level. For planting most useful are mineral and sandy soils, as well as clay and organic soils of quality classes III, IV and V. Additionally, this plant has great tolerance to $\mathrm{pH}$ of the soil ( $\mathrm{pH} 4.5$ to 7.6 ) [9-11].

In connection with the above issues studies were conducted to determine the possibility of using energy willow as a potential clean energy source. For this purpose the heat of combustion and calorific value of dry matter of the willow wood and bark were determined. From the point of view of environmental protection, to be able to treat this fuel as a clean energy source in the study the content of heavy metals was determined in the willow wood and soil on which the experimental plantation was located. In turn to specify the environmental impact the results were compared with permissible contents of individual metals in soil or ground determined in the Regulation of the Minister of Environment of 9 September 2002 on soil quality standards [12, 13].

\section{Experimental material}

The experimental material was willow wood taken from the experimental plantation. The experimental energy willow plantation is located in a small village Puczniew, Lutomiersk municipality, Pabianice district in the Lodz region. The village is located in the Ner river valley at Laska Upland.

The energy willow plantation was established at the initiative of the International Centre for Ecology, Polish Academy of Sciences and the University of Lodz. Within the plantation research is conducted on the use of phytoremediation for detoxification of aromatic compounds and for bioaccumulation of phosphorus compounds by the vegetation of ecotone zones.

Willow shrubs at the plantation were relatively young, about five years old only. The experimental material consisted of both willow bark and twigs of various diameters. From each shrub 8 to 12 samples were collected, depending on the shrub size and possibility of separation of individual samples. The samples were milled and averaged and then new, small samples weighing about 1 gram were formed to be mineralized. As part of the experiments performed each sample was tested in triplicate. The samples were stored in sealed plastic bags in the laboratory.

In the plantation four different willow species with different properties were grown, namely I - RAPP, II - ORM, III - JORRUN and IV - ULV. Willow species have different 
growth abilities which is related to different climatic and soil requirements. The factor that determines the willow growth rate is a sufficient amount of moisture accumulated in the soil, especially at the early stage of cultivation, and humus content. The first two willow species are characterized by higher resistance and faster growth [5, 14].

The first willow species - RAPP is located in the immediate vicinity of an irrigation ditch. Another species is grown about $15 \mathrm{~m}$ away from the ditch. The third species JORRUN is cultivated at a distance of $30 \mathrm{~m}$, and the last species IV - ULV is grown farthest away from the irrigation ditch at a distance of 50 meters.

Due to these differences in the properties of individual willow species, wood samples of all species were used in the study. In addition, soil samples from each species location were taken for testing.

The plantation is located on soil with worse quality classes where specific brown soils, leached and acid soils as well as podzolic and pseudopodzolic soils prevail. In order to fertilize barren soils this area is irrigated with river waters carrying wastewater purified in the Combined Wastewater Treatment Plant.

Due to the varying distance of individual tree stands from the irrigation ditch and varying inclination of the surface, there are different arrangements of groundwater table along the slope. The level of water table is $0.8 \mathrm{~m}$ below the ground surface at a distance of 1 meter from the irrigation ditch and 0.2 meters below the ground surface at a distance of 50 meters.

In connection with such diverse habitat conditions, soil samples were collected as a complementary research material which was analyzed for various man-made substances in the environment. Specific soil samples were collected at a depth of $30 \mathrm{~cm}$ at various distances from the irrigation ditch. Soil samples were appropriately labeled with Arabic numerals: 1 - soil samples taken in the immediate vicinity of the irrigation ditch, 2 - soil collected 15 meters from the ditch, 3 - soil samples taken in the plantation center, 4 - soil samples taken $50 \mathrm{~m}$ from the irrigation ditch.

From each place mentioned above three samples were taken. In total, 12 soil samples were collected and analyzed. The samples were stored in plastic sealed containers in the laboratory. After collection the samples were dried in a drying oven at $60^{\circ} \mathrm{C}$ for a week. The dried soil samples weighing about 1 gram were mineralized.

\section{Experimental methods}

The heat of combustion and calorific value of energy willow wood were determined according to the standard ISO 1928:2002 Solid fuels - Determination of the heat of combustion by the method of combustion in a bomb calorimeter and calorific value calculation. Determination of the heat of combustion by the calorimetric method consists in precise measuring the amount of heat generated during combustion of a known quantity of fuel in the bomb calorimeter (at constant volume) in oxygen under pressure when the products of combustion cool down to the room temperature. The amount of generated heat is determined by measuring an increase in the temperature of water in the vessel in which the bomb calorimeter is immersed. After introducing corrections which include additional thermal effects associated with heat transfer to the environment, the corrected temperature rise is multiplied by constant $\mathrm{C}$ (heat capacity of the calorimeter). From so calculated heat of combustion we subtract the heat of synthesis and dissolution of sulfuric and nitric acid formed in the process. The amount of acids is determined by titration $[15,16]$. 
The content of lead, cadmium, zinc, copper, nickel and chromium in the biomass and soil samples was determined using one of the oldest methods of chemical analysis flameless Atomic Absorption Spectrometry (AAS). This is an instrumental technique which is used to determine even trace amounts of various elements in various materials and media.

The method consists in absorbing radiation of a characteristic wavelength by free atoms of a given element. The Atomic Absorption Spectrophotometry is based on the measurement of absorption of electromagnetic radiation by substances in a quite broad range from 180 to $900 \mathrm{~nm}[17,18]$.

In this method, the electronic atomization in graphite furnace atomizers is used in order to obtain atomic gas. The device is electrically heated in four stages. In the first stage water is evaporated from the sample at the temperature $100-200^{\circ} \mathrm{C}$ in time of up to several tens of seconds. In the second stage the sample is mineralized. The temperature and time of this stage depend on the sample material. In the third stage, when the temperature reaches 1000 to $3000^{\circ} \mathrm{C}$ the evaporation and atomization of the sample take place. The process lasts for several seconds. In the last stage the sample is removed from the furnace before the next measurement cycle [17].

Wood and soil samples were mineralized in a Milestone microwave mineralizer. Mineralization took $25 \mathrm{~min}$. Triple samples of wood and soil were mineralized. Each of these samples was subjected to an independent analysis and the results which are shown in the graph are the arithmetic means of the results. The results differed by up to $15 \%$.

\section{Results}

Figure 1 shows the calorific value of willow wood and bark, depending on the sort and thickness of material being tested and energy willow species.

Based on the results it can be concluded that the calorific value of the whole willow sample ranged from 10 to $14 \mathrm{MJ} / \mathrm{kg}$ d.m., with about 6-12 MJ/kg d.m. being the calorific value of wood. The best species from the point of view of energy concentration, i.e. with the highest calorific value, appeared to be the last tested species, JORRUN. In the case of this species the calorific value was at the level of 10.2 to $14.1 \mathrm{MJ} / \mathrm{kg} \mathrm{d} . \mathrm{m}$. For RAPP, ORM and ULV species the calorific value was 10.6-14 MJ/kg d.m., 10.2-12.7 MJ/kg d.m. and 9.8-11.6 MJ/kg d.m., respectively.

a)

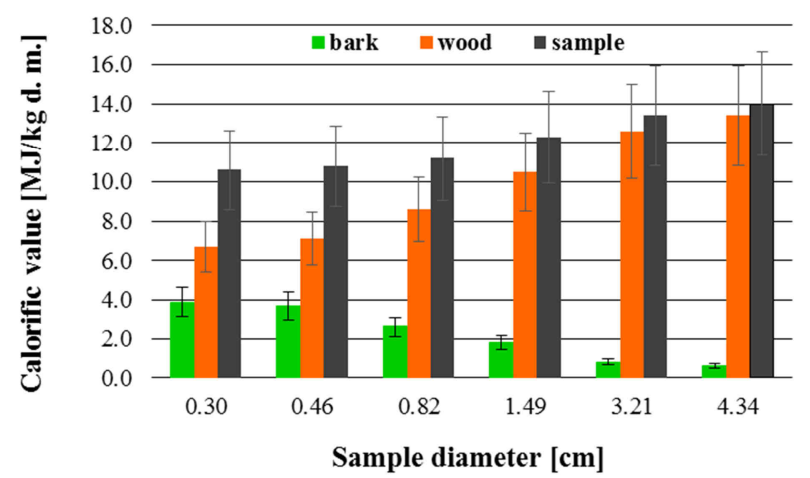


b)

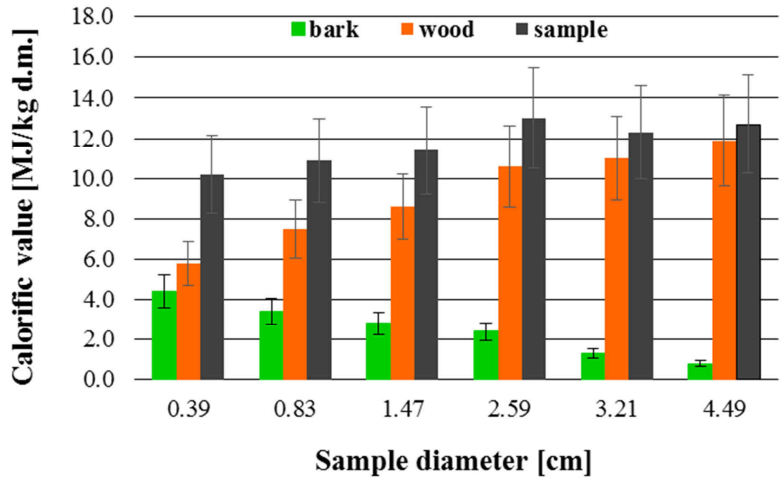

c)

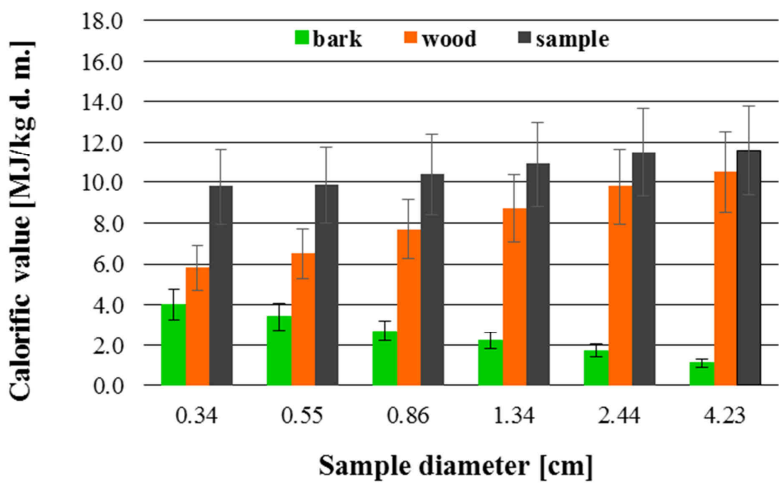

d)

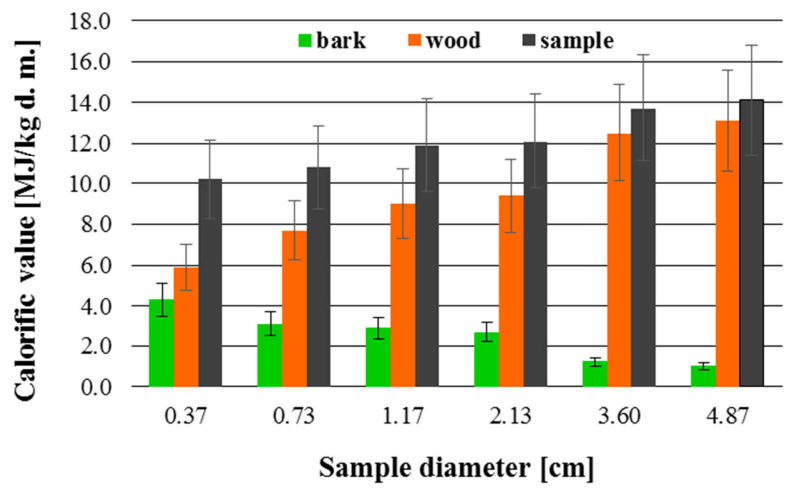

Fig. 1. Calorific value of the tested species of energy willow: a) RAPP, b) ORM, c) ULV, d) JORRUN

Figure 2 shows the results of heavy metals content of tested species of energy willow wood and in the soil coming from the plantation. Based on the above results, we can conclude that the concentration of zinc is the highest among heavy metals analyzed in the willow wood samples. Its content ranges from $78 \mathrm{mg} / \mathrm{kg} \mathrm{d.m.} \mathrm{(JORRUN)} \mathrm{to} \mathrm{about}$ 
$124 \mathrm{mg} / \mathrm{kg}$ d.m. (RAPP). In the soil samples, zinc concentration is much higher reaching the level of $93 \mathrm{mg} / \mathrm{kg}$ d.m. (soil samples for JORRUN species) to $263 \mathrm{mg} / \mathrm{kg} \mathrm{d.m}$. (soil samples for ULV species).

In turn, the content of cadmium and nickel in both wood and soil samples is small, amounting to $1 \mathrm{mg} / \mathrm{kg} \mathrm{d.m}$. for cadmium and $5 \mathrm{mg} / \mathrm{kg} \mathrm{d.m}$. for nickel. A deviation from the trend is observed in the case of RAPP and ULV species, where there is an increased concentration of nickel in the soil - $24 \mathrm{mg} / \mathrm{kg} \mathrm{d} . \mathrm{m}$. for RAPP and $38 \mathrm{mg} / \mathrm{kg} \mathrm{d}$.m. for ULV.

The lead content in different species of willow wood is similar, $35 \mathrm{mg} / \mathrm{kg}$ d.m. Completely different changes are observed in the case of lead in the soil. The concentration is very diverse and ranges from $19 \mathrm{mg} / \mathrm{kg}$ d.m. in the JORRUN species to $106 \mathrm{mg} / \mathrm{kg}$ d.m. in ULV.

The copper content in the willow wood in the first two species (RAPP, ORM) is the same, i.e. $40 \mathrm{mg} / \mathrm{kg}$ d.m. In the two other species copper content decreases gradually reaching the level of $28 \mathrm{mg} / \mathrm{kg} \mathrm{d}$.m. for ULV and $24 \mathrm{mg} / \mathrm{kg} \mathrm{d} . \mathrm{m}$. for JORRUN. The content of this metal in soil samples was different: $31 \mathrm{mg} / \mathrm{kg}$ d.m. for RAPP, $14 \mathrm{mg} / \mathrm{kg} \mathrm{d.m}$. for ORM, $65 \mathrm{mg} / \mathrm{kg}$ d.m. for ULV and $11 \mathrm{mg} / \mathrm{kg}$ d.m. for JORRUN.

The content of chromium in both willow wood and soil is also very different like in the case of copper. The content of this metal in wood ranges from $22 \mathrm{mg} / \mathrm{kg} \mathrm{d} . \mathrm{m}$. (ULV) to $36 \mathrm{mg} / \mathrm{kg} \mathrm{d.m}$. (RAPP), while in soil it is in the range from $13 \mathrm{mg} / \mathrm{kg} \mathrm{d.m}$. (JORRUN) to $95 \mathrm{mg} / \mathrm{kg}$ d.m. (ULV).

a)

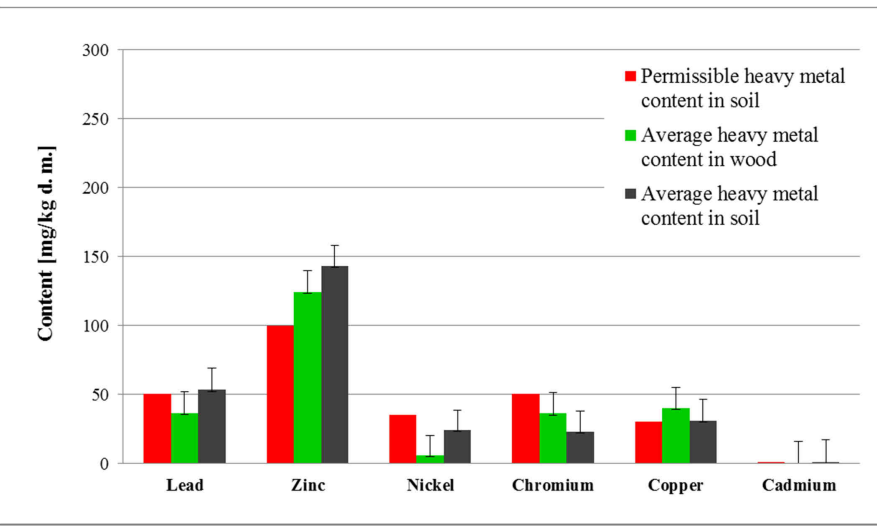

b)

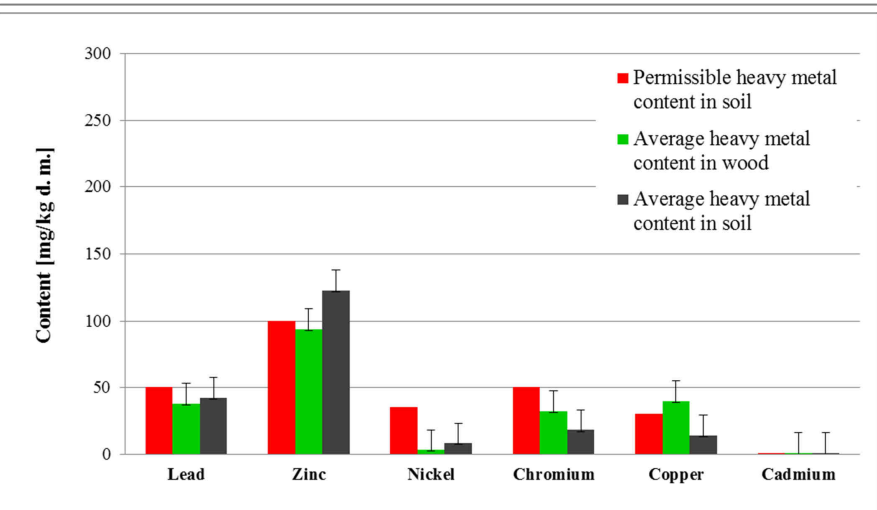


c)

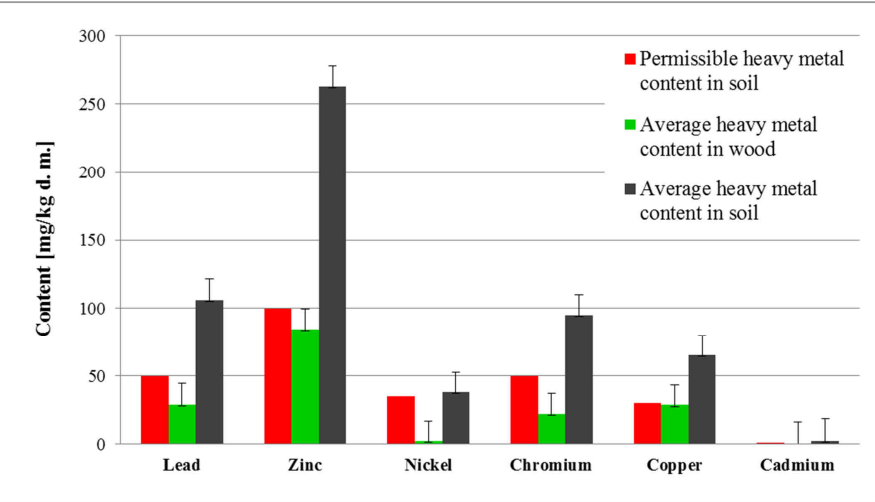

d)

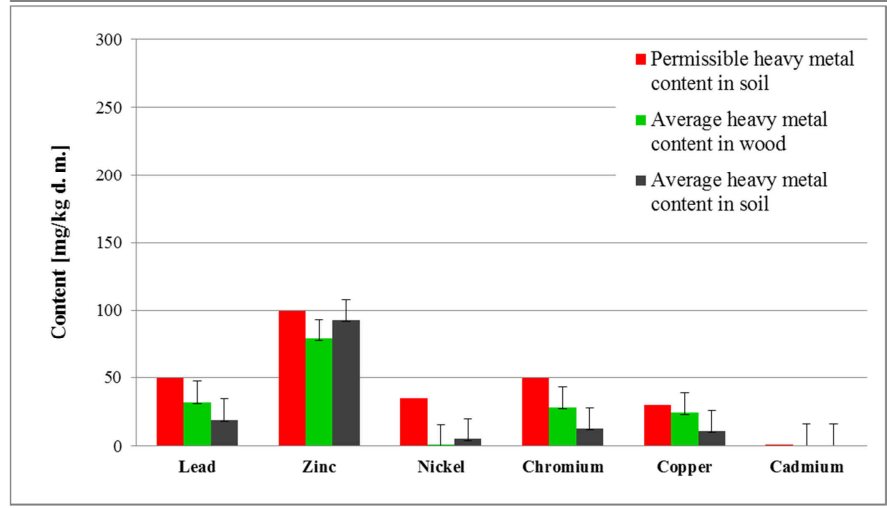

Fig. 2. Heavy metals content of tested species of the energy willow: a) RAPP, b) ORM, c) ULV, d) JORRUN

\section{Discussion}

Based on the results it can be concluded that the average calorific value of willow sample fluctuated around $12 \mathrm{MJ} / \mathrm{kg}$ d.m., where about $10 \mathrm{MJ} / \mathrm{kg} \mathrm{d.m.} \mathrm{was} \mathrm{the} \mathrm{average}$ calorific value of wood. The highest calorific value of $14.1 \mathrm{MJ} / \mathrm{kg} \mathrm{d.m}$. was obtained for a sample $4.9 \mathrm{~cm}$ in diameter for JORRUN species, while the lowest one of $9.8 \mathrm{MJ} / \mathrm{kg}$ for a sample with the smallest diameter $0.3 \mathrm{~cm}$ for ULV species. The results confirm that the calorific value depends strictly on the tested sort of willow wood, wood sample thickness and its position in the tree structure and finally on willow species which is in agreement with the literature data [19-22].

These results confirm very large individual differences in the content of heavy metals in both osier wood and soil samples in the area of cultivation of a given willow species. The heterogeneity and variable content of heavy metals depend primarily on willow species cultivated in particular areas of the experimental plantation. In addition, the concentration of heavy metals depends on soil conditions, in particular the level of water table.

The greatest average content of zinc and lead in the wood of energy willow is observed in the case of the first two varieties, i.e. RAPP and ORM. These varieties are characterized by the most extensive root systems through which metals are taken up by the plant and 
incorporated into its structure. A significant impact of the content of metals in the energy willow has also the degree of willow wood contamination with these metals. The higher the concentrations of these metals in the soil, the more of them pass to the plant structure.

It should also be noted that only in soil samples taken from the area of JORRUN species cultivation the permissible content of heavy metals in the soil was not exceeded. In the case of the RAPP species the permissible zinc content was exceeded by almost $50 \%$. Zinc content in the soil was $143 \mathrm{mg} / \mathrm{kg} \mathrm{d.m}$., while its acceptable level is $100 \mathrm{mg} / \mathrm{kg}$ d.m. For the same species a slightly exceeded level of lead and copper (by $1 \mathrm{mg} / \mathrm{kg} \mathrm{d.m}$.) was also observed. A slightly exceeded content was reported in the ORM species. In this case, only the content of zinc in the soil was exceeded. The worst results were obtained for soil samples taken from the plantation of ULV species. The content of each investigated metal was higher than the permissible content of heavy metals in the soil as specified in the Regulation of the Minister of the Environment of 9 September 2002 on soil quality standards. The obtained results are compatible with previous literature reports. We are seeing only slight variations depending on the variety of the tested energy willow [23-25].

This condition results from the furthest position of this variety from the irrigation ditch where soil has low moisture content, and hence heavy metals are not washed out.

\section{Conclusions}

An analysis was carried out to determine the suitability of energy willow as a potentially clean source of energy generated in the combustion process. For this purpose the heat of combustion, calorific value and content of some heavy metals in the willow wood and soil from the experimental plantation were determined.

Results of the tests revealed a close relationship between the calorific value and thickness of wood and its position in the tree structure. The average calorific value of the willow sample fluctuated around $12 \mathrm{MJ} / \mathrm{kg} \mathrm{d} . \mathrm{m}$.

In the process of burning the willow wood, metals contained in it may either be oxidized or remain in the ash. As a result, due to a possible use of the ash as a fertilizer, for soil improvement and remediation, it gets to the natural environment. Chemical composition of the ash produced from biomass, especially heavy metal content, determines its use as a fertilizer [13].

In order to determine the environmental impact, the results were compared with the limit values of these metals in the soil determined in the Regulation of the Minister of Environment of 9 September 2002 on soil quality standards. As a result, it was found that the wood of willow cultivated for energy purposes in field conditions contained certain amounts of heavy metals. Concentration of these metals in the wood depends on their content in the habitat soil $[25,26]$. The occurrence of these elements in the ash from willow wood combustion will be an obstacle to its agricultural use. Among trace elements, the ash from willow wood contains more zinc and lead, while the content of cadmium and nickel is several times lower. At the same time this may suggest that willow cultivation reduces the content of heavy metals in the ecosystem [27, 28].

Based on the results, it can be concluded that the willow biomass as an energy fuel provides raw material for sustainable energy production. However, the content of heavy metals in the wood causes that ash obtained in the combustion process repollutes the environment. The willow biomass can be used either as a primary fuel generated in the combustion process, or secondary one, i.e. biomethanol. Ash content obtained from a single 
ton of willow biomass is about $1 \%$ of the burnt biomass, while during combustion of low-grade coal it is as high as $20 \%$. The use of willow as a heat source reduces the problem of ash storage and disposal.

Due to the above mentioned characteristics confirmed by studies, willow species can be used to remove heavy metals, toxic and other compounds from the soil by incorporating them into the biomass. Willow roots capture more than $80 \%$ of the pollutants $[11,12]$.

The use of energy willow is very beneficial from the point of view of environmental protection, the use of fallow land, management of degraded land and reclamation of contaminated sites. These advantages cause that this raw material will be a response to the future demand for fuel for the Polish agriculture, power engineering and business which makes its cultivation very promising [26-28].

To sum up, the development of energy willow cultivation may contribute to a significant reduction of the content of heavy metals in soil, obtaining a new and renewable energy source and creation of new jobs in the regions with particular risk of unemployment. In light of the above, empirical researches on the applicability of energy willow and its effect on the environment are of crucial importance.

\section{References}

[1] Lindroth A, Bath A. Assessment of regional willow coppice yield in Sweden on basis of water availability. Forest Ecol Manage. 1999;121:57-65. DOI: 10.1016/S0378-1127(98)00556-8.

[2] Stolarski JM, Szczukowski S, Tworkowski J, Klasa A. Willow biomass production under conditions of low-input agriculture on marginal soils. Ecol Manage. 2011;262:1558-1566. DOI: 10.1016/j.foreco.2011.07.004.

[3] Chum, HL, Overend RP. Biomass and renewable fuels. Fuel Process Technol. 2001;71:187-195. DOI: 10.1016/S0378-3820(01)00146-1.

[4] Long, H, Li X, Wang H, Jia J. Biomass resources and their bioenergy potential estimation: A review. Renew Sust Energy Rev. 2013;26:344-352. DOI: 10.1016/j.rser.2013.05.035.

[5] Kuzovkina AY, Volk AT. The characterization of willow (Salix L.) varieties for use in ecological engineering applications: Co-ordination of structure function and autecology. Ecol Eng. 2009;38:1178-1189. DOI: 10.1016/j.ecoleng.2009.03.010.

[6] Jezierska-Thole A, Rudnicki R, Kluba M. Development of energy crops cultivation for biomass production in Poland. Renew Sust Energ Rev. 2016;62:534-545. DOI: 10.1016/j.rser.2016.05.024.

[7] Obernberger T, Bruner T, Barnthaler G. Chemical properties of solid biofuels - significance and impact. Biomass Bioenerg. 2006;30:973-982. DOI: 10.1016/j.biombioe.2006.06.011.

[8] Linderson ML, Iritz Z, Lindroth A. The effect of water availability on stand-level productivity, transpiration, water use efficiency and radiation use efficiency of field-grown willow clones. Biomass Bioenerg. 2007;31:460-468. DOI: 10.1016/j.biombioe.2007.01.014.

[9] Field CB, Campbell JE, Lobell DB. Biomass energy: the scale of the potential resource. Trends Ecol Evolution. 2008;23: 65-72. DOI: 10.1016/j.tree.2007.12.001.

[10] Carneiro P, Ferreira P. The economic, environmental and strategic value of biomass. Renew Energy. 2012;44:17-22. DOI: 10.1016/j.renene.2011.12.020.

[11] Ledin S. Willow wood properties, production and economy. Biomass Bioenerg. 1996;11:75-83. DOI: 10.1016/0961-9534(96)00022-0.

[12] Martin PJ, Stephens W. Willow growth in response to nutrients and moisture on a clay landfill cap soil. II: Water use. Bioresour Technol. 2006;97:449-458. DOI: 10.1016/j.biortech.2005.03.004.

[13] Mirck J, Volk TA. Response of three shrub willow varieties (Salix spp.) to storm water treatments with different concentrations of salts. Bioresour Technol. 2010;101:3484-3492. DOI: 10.1016/j.biortech.2009.12.128.

[14] Mleczek M, Rissmann I, Rutkowski P, Kaczmarek Z, Golinski P. Accumulation of selected heavy metals by different genotypes of Salix. Environ Exper Bot. 2009;66:289-296. DOI: 10.1016/j.envexpbot.2009.02.010.

[15] Dimitriou I, Eriksson J, Adler A, Aronsson P, Verwijst T. Fate of heavy metals after application of sewage sludge and wood-ash mixtures to short-rotation willow coppice. Environ Pollut. 2006;142:160-169. DOI: 10.1016/j.envpol.2005.09.001. 
[16] Stolarski JM, Szczukowski S, Tworkowski J, Krzyżaniak M. Cost of heat energy generation from willow biomass. Renew Energy. 2013;59:100-104. DOI: 10.1016/j.renene.2013.03.025.

[17] Wuilloud JCA, Wuilloud RG, Vonderheide AP, Caruso JA. Gas chromatography/plasma spectrometry an important analytical tool for elemental speciation studies. Spectrochim Acta. 2004;59:755-792. DOI: 10.1016/j.sab.2004.03.009.

[18] Ebdon L, Evans EH, Fisher A, Hill SJ. An Introduction to Analytical Atomic Spectometry. Plymouth: Wiley; 1998.

[19] Abbasi T, Abbasi SA. Biomass energy and the environmental impacts associated with its production and utilization. Renew Sust Energy Rev. 2010;919-937. DOI: 10.1016/j.rser.2009.11.006.

[20] Demirbas A. Combustion characteristics of different biomass fuels. Progress Energy Combust Sci. 2004;30:219-230. DOI: 10.1016/j.pecs.2003.10.004.

[21] Carroll J, Finnan J. Emissions and efficiencies from the combustion of agricultural feedstock pellets using a small scale tilting grate boiler. Biosys Eng. 2013;115:50-55. DOI: 10.1016/j.biosystemseng.2013.01.009.

[22] Fang S, Xue J, Tang L. Biomass production and carbon sequestration potential in poplar plantations with different management patterns. J Environ Manage. 2007;85:672-679. DOI: 10.1016/j.jenvman.2006.09.014.

[23] Nixon DJ, Stephens W, Tyrrel SF, Brierley EDR. The potential for short rotation energy forestry on restored landfill caps. Bioresour Technol. 2001;77:237-245. DOI: 10.1016/S0960-8524(00)00081-X.

[24] Williams JM, Jones LM, Pourkashanian M. Pollutants from the combustion of solid biomass fuels. Progress Energy Combust Sci. 2012;38:113-137. DOI: 10.1016/j.pecs.2011.10.001.

[25] Ghafghazi S, Sowlati T, Sokhansanj S, Bi X, Melin S. Particulate matter emissions from combustion of wood in district heating applications. Renew Sust Energy Rev. 2011;15:3019-3028. DOI: 10.1016/j.rser.2011.04.001.

[26] Ericsson K, Rosenqvist H, Ganko E, Pisarek M, Nilsson L. An agro-economic analysis of willow cultivation in Poland. Biomass Bioenerg. 2006;30:16-27. DOI: 10.1016/j.biombioe.2005.09.002.

[27] Adler A, Dimitriou I, Aronsson P, Verwijst T, Weih M. Wood fuel quality of two Salix viminalis stands fertilized with sludge, ash and sludge-ash mixtures. Biomass Bioenerg. 2008;32:914-925. DOI: 10.1016/j.biombioe.2008.01.013.

[28] Vassilev SV, Vassileva CG, Vassil SV. Advantages and disadvantages of composition and properties of biomass in comparison with coal: An overview. Fuel. 2015;158:330-350. DOI: 10.1016/j.fuel.2015.05.050. 